\title{
Study on B2C Transactions of Agricultural Products in China
}

\author{
Yuan-Yuan LAI, Shu-Bin ZHAN* \\ Qingdao Agricultural University \\ Qingdao, 266109, China \\ laiyuanyuan@163.com, kingweilee@163.com \\ *Corresponding author
}

\begin{abstract}
This paper attempts to study the development trend and requirements of $\mathrm{B} 2 \mathrm{C}$ e-commerce of agricultural products. The paper analyzed about the present situation of Chinese agricultural B2C, found its characteristics of diversification of sales model and sales principal. By CNNIC survey data analysis, concludes with recommendations including attaching great importance to the brand and user evaluation, strengthen the construction of supporting infrastructure, Cultivating agricultural e-commerce talents.
\end{abstract}

Keywords- B2C, Agricultural products, User evaluation, Logistics, Home delivery

\section{INTRODUCTION}

China's agricultural products market circulation pattern is in an important differentiation stage. In addition to the traditional wholesale market, bazaar, supermarket, and other circulation channels, e-commerce is going to the people life. In 2012 the national agricultural products network sales size is about 20 billion RMB, accounting for $1 \%$ of the total sales in circulation. By December 2013, the size of China's Internet users reached 618 million, a total of 53.58 million Internet users increased throughout the year. Internet penetration rate is 45.8\%, a 3.7\% increase at the end of 2012 . There is still large room for agricultural products network sales to grow up in the future.

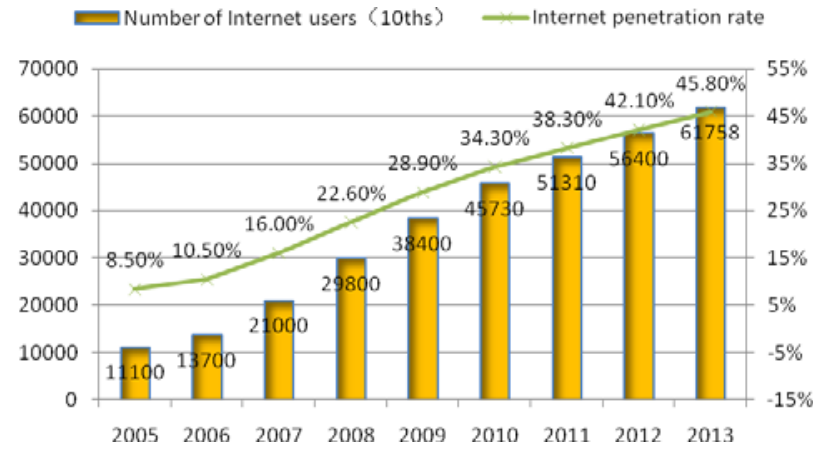

Fig. 1, Size of China's Internet users and Internet penetration Sources of data : CNNIC survey of Internet development in China 2013.12

Agricultural product network marketing can take a variety of ways such as booking and group-buying. This can be done with plans of picking, fishing or processing. On the one hand, it can make the maximum maintenance of the biological characteristics of agricultural products, reduce the cost of agricultural products storage and make consumers get more fresh produce. On the other hand it reduces the information asymmetry between the seller and the buyer. This becomes a new way of thinking to solve the problem of agricultural products sold at a loss but buy expensive.

Compared to the traditional channels, e-commerce site can better respond to food safety in the "trust" issue. In traditional agricultural product circulation, because too many intermediaries, consumers can't see the real producers, producers also won't see consumers. This makes serious asymmetric information of production and marketing of agricultural products, the product quality is difficult to trace back and are prone to a crisis of confidence. B2C (Business to Customer) electronic commerce has changed this situation. Taobao's ecological agriculture channel, for example, in shops, all the farmer's information and indicate the producer, production process and the agricultural product safety standards, such as information disclosure, certificate and organic farm yards and other data and China certification and accreditation information network data center directly. Consumers can learn about the agricultural products from the commodity information how where is the production base, production environment, production specifications, an effective certification and qualification, and so on, and use organic authenticity code check on the product packaging, thereby reassuring consumption and consumption.

\section{B2C IN THE CURRENT SITUATION OF CHINESE AGRICULTURAL PRODUCTS TRADE}

With the in-depth development of the Internet economy, agricultural renders booming e-commerce activity, reflected in the following aspects: First, there have been a large number of agricultural products sales sites. Consumer tries to connect the network to purchase agricultural products. Farmers Markets and supermarkets are the main channel of agricultural products in the past. With the popularization of computer technology, communications technology and network technology, agricultural Web sites have sprung up in emerging. Consumers are embracing B2C(Business-toCustomer) marketing mode of agricultural products. In 2012, the quantity of shop engaged in agricultural products is over 0.26 million in Taobao and TMALL, 10.04 million agricultural products are involved. As of 2013, agricultural outlets may have exceeded 1 million.

The second is, the types and sales of the in $\mathrm{B} 2 \mathrm{C}$ are increasing. Take Taobao as an example, in 2010 the categories of agricultural products involving agricultural products mainly based on dry mountain goods, cereals, rice, flowers and gardening, completed sales of 3.735 billion RMB. In 2011, the categories increasing such as fruits and vegetables, flowers, plants, and trees, total sales of 11.366 
billion RMB. In 2012 it increased tea and fresh seafood for two broad categories of accounts, sales of agricultural products reached 19.861 billion RMB. In 2013, almost all purpose agricultural marketing in Taobao has been a high rate of growth, some in key categories such as fresh fruit, seafood, North and South dry goods and fresh vegetables increase can be over $300 \%$.

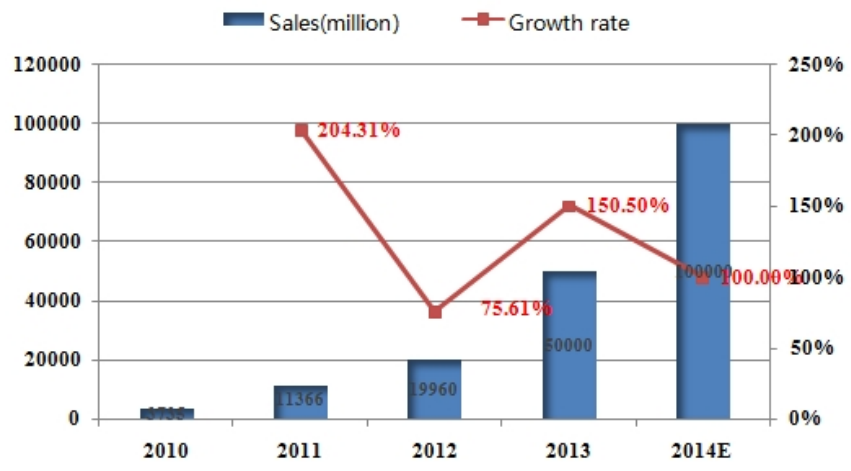

Fig. 2, The agriculture goods sales in Ali platform

Sources of data : Reports in AliResearch (http://www.aliresearch.com)

\section{CHARACTERISTICS OF THE CURRENT DEVELOPMENT OF AGRICULTURAL PRODUCTS B2C}

One is that agricultural $\mathrm{B} 2 \mathrm{C}$ marketing mode diversification. In addition to the major agricultural products sales sites, sellers of agricultural products widely use of third-party electric business platform provides a variety of ways, such as groupon, Twitter marketing, micro-sales and so on. Some brands B2C website, according to different area every day there are certain types of group purchase of agricultural products, convenient for residents in the region. Social platform also provides a convenient for agricultural products promotion and sales. Using social networking platforms such as micro-blog, Twitter, sellers can promote products or direct selling of agricultural products, and then by express service and home delivery sent directly to consumers.

The other is agricultural B2C sales subject diversification. Early development of e-commerce, B2C sales of agricultural products mostly are agricultural dealers. With the popularization of computer technology and network technology, agricultural producers are also beginning to use network to sales. Investigations revealed that the scale farmers ' professional cooperatives tend to control channels, build B2C sales websites or use a third-party platform. Some e-commerce platforms set up a special channel of agricultural products, organize agricultural dealers to participate in, with the help of e-commerce enterprise brand effect formed its own sales channels. For the characteristics of high logistics requirements of agricultural products, a number of third-party logistics companies are also beginning to seize the farm produce market, build websites for agricultural products sales, such as sfbest.com.

\section{PROBLEMS IN THE AGRICULTURAL PRODUCTS B2C IN} CHINA

Although agricultural e-commerce in China developed rapidly, its restricting factors are many. First, it is a low degree in standardization of agricultural products, the quality information of the product is difficult to obtain. China's agricultural production is still dominated by scattered peasant households, so standardization of production has not yet formed, production process control does not implement the informatization, and farm produce traceability system has not been established. Consumers are difficult to obtain information on the agricultural production process. In the current agricultural B2C marketing, usually only a brief description is provided of the appearance on the agricultural products, such as size grading, but on the degree of fresh, nutrients, pesticides and other important indicators without description, lack of professional test report. Consumers lack information in the selected direction, can only refer to the brand, user ratings and other information, so there is a great deal of blindness.

Second, the logistic distribution system is not perfect, with low levels of logistics services. Agricultural products with fresh, perishable, not resistant to storage and other features, requires special conditions of storage, distribution and transport. However China's express delivery industry less competitive, cold-chain logistics technology development and promotion of lag issue cannot meet the requirement of agricultural e-commerce. In the B2C of agricultural products, packaging damaged, does not arrive on time and product deterioration is the frequent complaints of consumers.

Three is weak information based and a lack of professional talents. National average Internet penetration rate is only $45.8 \%$ and larger regional differences. Such as Beijing, Shanghai, Guangdong the Internet penetration rate reached about $70 \%$, Guizhou, Yunnan, Jiangxi and some other regions, but penetration was only about $32 \%$. In the field of logistics, due to factors such as technology and cost, logistics information technology such as GPS, RFID used in the circulation of agricultural products is less, can't provide good support for agricultural e-commerce. At the same time, agriculture-related e-commerce talents lacking at the national level. Professional information technology personnel and online marketing talent is very rare in rural distribution. few peasants could access internet and make the web page. Many agriculture enterprises experienced difficulties in recruiting talented people to take advantage of modern network information tool for online sales.

In addition, the traditional trading habits and not convenient to pay is also important factor restricting the development of agricultural e-commerce.

\section{COUNTERMEASURES AND SUGGESTIONS}

First is the establishment of agricultural standardization system. Standardization is a prerequisite for B2C scale development of agricultural products. Only for agricultural products in terms of quality specification grade classification, such as grading, it could become a standardized product. In 
this case consumers would accept products through the circulation of electric business platform under the condition of the invisible. Standardization system building needs from production to sale of technical guidance and standards for the implementation of the whole process. From the seed selection, the use of chemical fertilizers, agricultural cultivation process to the classification and grading of agricultural products, storage, packaging and transport after harvest, shall establish a comprehensive system of quality standards. Products that meet certain quality standards must be strictly in accordance with the system requirements for production and sales. It is actually decentralized production to intensive production process. This process involves many technical, policy, and many other conditions, so it is complex and long.

In front of the standardized system has not been established, the enterprise must attach importance to brand building and user evaluation. By setting up a good brand image to attract and stable customer group, ensure the quality of agricultural products, replacing part of the quality standards by brand effect. At the same time attaches great importance to the customer service and user evaluation. In the process of e-commerce transactions, consumers select products with a major factor to consider is the user evaluation as shown in Figure 3 and Figure4. A welldocumented negative feedback will have a very great negative impact. Therefore, the enterprise should be allround customer service, to ensure high customer satisfaction.

= Popularity and word-of-
mouth of website
= Previous shopping
experiences
n' Distribution and after-
sales service
m User evaluation
= Web brand
= Discount/git

Fig. 3, The factors considered for buy unfamiliar products online Sources of data: CNNIC China's online shopping market survey 2013.11

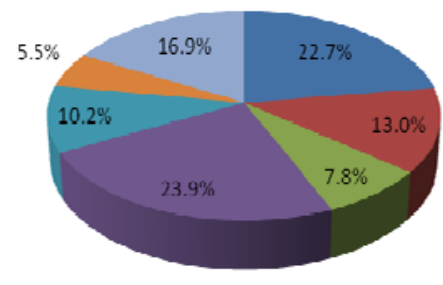

$$
\begin{aligned}
& \text { nopularity and word-of- } \\
& \text { mouth of website } \\
& \text { n Previous shopping } \\
& \text { experiences } \\
& \text { nistribution and after- } \\
& \text { sales service } \\
& \text { n User evaluation } \\
& \text { m Web brand } \\
& \text { n Discount/gift }
\end{aligned}
$$

Fig. 4, The factors considered for buy familiar products online Sources of data: CNNIC China's online shopping market survey 2013.11
Secondly, establish and perfect the agricultural products logistics and distribution system. Should through the government capital, strengthen the agricultural refrigerated storage system and the construction of fresh agricultural products distribution center, the construction of the complete green distribution channels, and attaches great importance to the third party logistics of agricultural products, encouraging business investment, satisfy people's demand for agricultural products in the form of marketization. For companies, on the one hand to develop delivery logistics, and inter-firm cooperation, planning of rational distribution route, increase delivery speed. Using advanced packaging technology on the other hand, increase the use of cold chain technology, improve the level of logistics service, and attach importance to the quality of fresh agricultural products.

Third, strengthen information network construction and cultivate talents of agricultural e-commerce. Mainly depends on the government's attention and financial investment, give full play to the government guidance leading role of financial capital, increasing capital input to the agricultural informatization construction. Accelerate the progress of rural network establishment and network quality and in a timely manner to agricultural science and technology knowledge and product market information through the network as a public goods provided to businesses and consumers. Attaches great importance to the training and technical guidance to farmers, not only to teach agricultural production technology, also taught modern information technologies and business, engaged in agricultural products for the future of network marketing to lay a theory foundation.

\section{ACKNOWLEDGMENT}

This article was financially supported by the research project of the Shandong Province Soft Science Research Project of 2013 (Grant No. 2013RKB01104).

\section{REFERENCES}

[1] Goldstein A, O'connor D, "E-commerce for development: prospects and policy issues”, OECD Development Centre, Paris, 2000.

[2] Huang, Lijuan, and Pan Liu. "Key Technologies and Alogrithms' Application in Agricultural Food Supply Chain Tracking System in E-commerce." Computer and Computing Technologies in Agriculture VII. Springer Berlin Heidelberg, 2014, pp. 269-281.

[3] Wen, Q, “Agricultural product network marketing research,” China's trade. Oct. 2012, pp. 96-97

[4] 33th Statistical Survey on the Development of Internet in China, EPublishing, China Internet Network Information Center(CNNIC), 2014, pp. 35-63

[5] Information on http://www.aliresearch.com 